\title{
Daniel K. Cortese, Are We Thinking Straight? The Politics of Straightness in a Lesbian and Gay Social Movement Organization. New York and London: Routledge, 2006. 213 Pp. ISBN 0-4I5-9770I-0. $£ 45.00$.
}

Built upon resource mobilization, political opportunity and framing theories, Cortese takes the example of the Straight and Gay Alliance (SAGA) in the USA to examine the role of straight-identified people within LGBT organizations. The author is interested in exploring the reasons underpinning the political success achieved by SAGA in the last 10 years and whether the inclusion of 'allies' - a notion used to describe straight members - accounts for those outcomes.

A stimulating aspect in this book is how conflicting identities are brought together to build a coalition in which the movement core does not self-destruct, but rather, is enhanced by the presence of those conflicting identities. According to Cortese, this is particularly challenging in the case of LGBT organizations which aim at promoting the rights of people who are defined by their sexual orientation or gender identity, which is opposed to heteronormativity. Thus, heterosexuals are, by definition, the 'other' of LGBT politics, and this process of othering is often looked upon as constitutive of LGBT identities as such.

Cortese also analyses how local-based affiliations of SAGA deploy the 'straight identity' in order to achieve specific aims. Based in the theory of identity deployment advanced by Mary Bernstein, Cortese concludes that straightness in LGBT organizations is used either to obtain more legitimacy in the public sphere (particularly among policymakers) or to enlarge membership networks and fundraising sources. Cortese also suggests SAGA uses straight people to represent LGBT politics to the more conservative constituencies in the US.

Looking at how identity deployment strategy is framed, Cortese argues that SAGA's experience highlights the possibility of overcoming culture wars, to the extent that former competing perspectives can be articulated to produce a mixed but winning strategy:

I found that SAGA bridges together these two frames (moral and injustice), and permits the inclusion of straight people into the organization. By doing so, straight people who join SAGA may, in their personal lives and through their social networks, bridge together the straight and gay communities in their shared quest to fulfill the mission of SAGA. (p. 25)

This sense of 'mission' acknowledged by several of the 30 interviewees in the study also contributed to the overcoming of culture wars. In fact, Cortese innovatively shows how the Christian faith has in some cases determined members' involvement in the struggle against homophobia, which they view through the lens of their moral duty towards society.

Sexualities Copyright $@ 2008$ SAGE Publications (Los Angeles, London, New Delhi and Singapore) Vol II(3): 375-384 DOI: 10.1 I77//363460708089427

http://sex.sagepub.com 
An additional significant feature of this book is the clear methodological account the author provides, with detailed explanation of how doing fieldwork and qualitative analysis can work, thus constituting an invaluable tool for students and researchers.

As a whole, the book could benefit from a more detailed analysis of straight identities. I specifically identify two types of problem in the way Cortese considers straightness. First, the author often implies a certain perplexity about people who want to struggle against their own rights. By doing so, Cortese disregards the fact that a non-heteronormative society would benefit everyone, including straightidentified people who reject stereotypical gender roles or family arrangements, for instance. Second, the author seems unaware of the diversity within the category of 'straight', which is often treated homogenously. By describing straights as 'allies', thus reinforcing differences already present in the organization itself, Cortese seems to bypass the potential of queer-straights (O'Rourke, 2005), furthering the image of queerness as a privilege shared by some, rather than an inclusive project. Both these criticisms could be avoided by simply replacing 'straight' or 'allies' by straight-identified members, conveying both democratic inclusion in the organization and the complexity of straight identities.

Nevertheless, overall this book constitutes an important contribution to the study of social movements, filling a previously existing gap on literature about the strategic deployment of straight identity, as well as its implications and pitfalls. Therefore this case study based on SAGA's experience is multilayered, fascinating and with a lot of potential, as Cortese aptly demonstrates.

\section{Reference}

O'Rourke, M. (2005) 'On the Eve of a Queer-Straight Future: Notes Toward an Antinormative Heteroerotic', Feminism Psychology 15(1): 111-16.

Ana Cristina Santos Centre for Interdisciplinary Gender Studies, University of Leeds, UK and Birbeck Institute for Social Research, University of London, UK

\section{Thomas Piontek, Queering Gay and Lesbian Studies. Urbana and Chicago: University of Illinois Press, 2006. I 32 pp. ISBN 0-252-07280-4.}

The past few years have witnessed the academic conflict between gay and lesbian studies on the one hand, and queer theory on the other. Actually, it is the other way around: queer theory - as the new critical vanguard - versus the old generation of gay and lesbian theorists/activists. This book is the latest contribution to this fierce academic warfare in the USA and its author clearly fights for the queer brigade. Fortunately, however, Thomas Piontek is not interested in throwing conceptual hand-grenades and then counting the casualties. Rather than an attack, this book is an invitation to consider why the adoption of a radically queer stand 